\title{
Dermatoglification Analysis for Selection and Training of Sports Talents
}

\author{
André Olímpio Martins ${ }^{1}$, Paula Matias Soares ${ }^{2}$, Welton Daniel Nogueira \\ Godinho $^{3}$, Guilherme Lisboa de Serpa ${ }^{4}$, Francisco Trindade Silva ${ }^{5}$ \\ ${ }^{1,4}$ (Universidade Estadual do Ceará, Brazil) \\ 2,3 (Universidade Estadual do Ceará, Instituto Superior de Ciências Biomédicas, Brazil) \\ ${ }^{5}$ (Faculdade Integrada do Ceará, Brazil)
}

\begin{abstract}
The term sports talent can be defined as the individual who, through his inherited and acquired conditions, has a special ability for sports performance, above the average of the general population. Fingerprints are genetic markers and can function as indicators of sporting talents. The objective of the present study was to use dermatoglyphics to identify the genetic-physical profile of soccer athletes. Twenty-four athletes belonging to the Palmeiras Sports Society Athletes' Capture Center participated in this study in the Nordeste sub-category category 16. The dermatoglyphic protocol of Cummins and Midlo (1961) was used. Standard fingerprint indices were calculated: the number of drawings for the 10 fingers and the delta index (D10). We also analyzed the types of digital formulas that indicate the representation in individuals of different types of drawings. Based on the classification of Fernandes (2002), the group presented somatofunctional classification for height, velocity and explosive strength, due to the delta index of 11.54. We conclude that dermatoglyphics can be a parameter to identify the potentiality of an individual and can be incorporated into a policy of selection and formation of sports talent.
\end{abstract}

Keywords: Dermatoglyphia, Sports Talent, Soccer, Training

\section{Introduction}

The term sports talent is already sufficiently clarified by the literature, and can be defined as the individual who, through his inherited and acquired conditions, has a special aptitude for sports performance, above the average of the general population (BÖHME, 1999) [1] Currently, within the world sporting scene, the search for talented young athletes capable of withstanding high training loads and high rates of technical improvement is great. The parameters that involve obtaining the maximum physical performance, the improvement of results and the breaking of records, have been object of study of many researchers of the sports area. Nowadays scientific knowledge has taken the place of empiricism, and there is no place for physical preparation that is not based on the physiological principles of physical training. However, we still find many coaches who work thinking that they will find talents based on virtuosity, where talent can be found by chance and by chance. For Dantas et al. (2004) [2], discovering talent can be compared to the work of seeking oil, it requires, above all, scientific knowledge. There is no more room for empiricism. When you dig a well to look for oil, you already have a fairly certain view of the percentage of chances of finding oil. In the case of gold mining, contrarily, gold appears through luck. The selection of talent, as well as the promotion of talent in football and any other sports, should be done by making scientific analysis, not by prospecting talent. It is believed that there are many children and adolescents deprived of genetic inheritance who are subjected to arduous training, hoping that they will achieve a great performance, and when it is perceived that their sporting future is not so promising, it has been a few years where much time and Work trying to achieve the impossible, as well as possible physical and psychological damages that systematic and intensive training can bring to those who do not have the least potential to become great athletes (Moskotova, 1998)[3].

Some abilities, such as flexibility, coordination of movements in time and space, reaction speed, local muscular endurance, are determined from the genetic point of view. However, the development of talent goes far beyond the anatomical and physiological components of the individual. Determination, decision, and an inflexible desire to win are no less important aspects to consider in this definition (BOUCHARD; LORTIE, 1984)[4]. Currently there is a great deal of concern within sports research to find methodologies that measure the genetic potential of athletes. In sports, dermatoglyphics is a technique used by many researchers, who point it out as a way of estimating an athlete's genetic potential. For Ferreira (2004) [5], through the study of dermatoglyphics one can obtain not only the maximization of sports performance, but also the correct direction of effort, time and money. In this way and with the intention of glimpsing the future and adequate performance of athletes, it is verified that the initial phase must obtain the contribution of dermatoglyphics through the obtaining of fingerprints. 
In his research, Borin (2002) [6] reports that the first form of classification of the fingerprints was proposed by Galton in 1891, based on the recognition of the deltas or trirddios as points of irradiation of the dermopapillary lines that form the typical configurations. Later, Vucetich (1904) [7] classified the patterns into four groups: arch, inner loop, outer loop and whorl, and in 1924, Bonnevie [8] presented a method for quantitatively estimating digital patterns and then Holt (1957) [9] replaced this methodology by the total count of lines formed by the crests, allowing greater precision in the quantitative evaluation of the results (Cummins and Midlo, 1961) [10] From the knowledge of the formation of the triad (delta) the authors mostly distinguish three groups of drawings: arch (A), loop (L) and together, whorl and S-drawing (W) (Figure 1). The shape of the drawings characterizes a qualitative feature. The number of lines is the sum of the total number of lines (SQTL), while the number of cutaneous ridges within the drawing represents the quantitative characteristic. In this sense, the biometric characteristics present both qualitative aspects represented by configurational patterns and the presence of flexural folds, as well as quantitative data given by row counting, indices formed by specific dermopapillary details, or angular measurements From this perspective, the present study aims to use dermatoglyphics to identify the genetic-physical profile of soccer athletes Belonging to the Center for Capture of Athletes of the Sociedade Esportiva Palmeiras in the Northeast category.

\section{Materials And Methods}

The study is a longitudinal, descriptive, direct and exploratory epidemiological study. Twenty-four athletes belonging to the Palmeiras Athletic Capture Center in the Northeast sub-16 category (athletes born between 1995 and 1994) participated in this study.For the collection of fingerprints, a specific ink for fingerprinting was used (BVDA brand), a small roller to dirty the ink finger and a fingerprint recorder. The present research complied with the ethical determinations contained in Resolution No. 196/96, which regulates research on human beings (BRAZIL, 1996). The standard fingerprint indexes were calculated: The number of drawings, of different types, for 10 (ten) fingers; The summary intensity of the drawings in the 10 (ten) fingers of the hands, or the delta index (D10); This is obtained, following the sum of deltas, from all drawings, so that the "evaluation" of Arc, (A) is always 0, and there is no delta; Of each Clamp, (L) 1 (one delta); Of each Verticilo (W) and S drawing 2, (two deltas), that is, $(\mathrm{L}+(2 * \mathrm{~W}))$; The types of digital formulas that indicate the representation in individuals of different types of drawings. A total of 8 (eight) types of digital formulas are identified: $10 \mathrm{~A}$ - ten arcs; AL - the presence of bow and loop, in any combination; ALW - the presence of bow, loop and whorl, in any combination; $10 \mathrm{~L}$ - ten cleats; $\mathrm{L}>\mathrm{W}$ - presence of a loop and whorl, with the condition that the number of loops is greater than $5 ; \mathrm{L}=\mathrm{W}$ - same hook number and whorl; $\mathrm{W}>\mathrm{L}$ - presence of loop and whorl, with the condition that the number of whorls is greater than 5;10w - ten whorls or S-deer;Analysis Protocol: The protocol for fingerprint analysis was that proposed by Cummins and Midlo (1961).

\section{Results And Dirscurssion}

Figure 2 shows the values for the delta index and right (MDT 1-5) and left (MET 1-5) types of the study group, where "0" is an arc, "1" tab And "2" upright. Figure 3 shows the average values for the types of drawings and delta index according to the position in the field. For values between 0.50 and less was considered arch; For values between 0.51 and 1.49 was considered a clamp; And for values above or equal to 1.50 was considered vertical.In figure 4 we can see the somatofunctional characteristics identified by the dermatoglyphics of the group studied from the delta index and the digital formula based on Dantas (2002). Dantas (2002) compiled the classification of fingerprint indices, based on analyzes of dermatoglyphic indices and somatofunctional indices of high-performance futsal athletes (Figure 8). This classification consists of five main classes, which are distinguished by the different functional dominant, so that the low intensity of drawings (D10) and the low sum of the total number of lines (LQTL) correlate with the high level of forca manifestations And power, but with a low level of coordination and resistance.In contrast, when the level of D10 and LQTS increases, there is a correlation with resistance and coordination. The maximum values of D10 and SQTL refer to the accentuation of coordination qualities of individuals.

Analyzing our results from the study of Fernandes and Dantas (2002) we found a predominance of the group in Class III, due to the average D10 of 11.54 (Figures 2 and 3), thus having a genetic predisposition for height, explosive strength and velocity. In figure 5 we noticed that the somatofunctional characteristics with the highest incidence were velocity and explosive force (62.50\% in both). Stature presented as the somatofunctional characteristic of lower incidence. Figure 6 shows the somatofunctional classification of the players studied from the dermatoglyphic indexes (delta index) separated by field positions. We can see that defenders and sides had a somatofunctional classification with maximum values for coordination, speed resistance and agility; Attackers received maximum values for height, speed and explosive force; The steering wheels presented maximum values for strength and speed; Socks, as well as the goalkeeper, showed speed, strength, explosive strength and stature as maximum values.Figure 7 shows the combination of the digital formulas expressed in percentages for the group. 


\section{Figures}

Fig. 1: Three groups of drawings; Bow (A), Clamp (L) and Verticle (W)

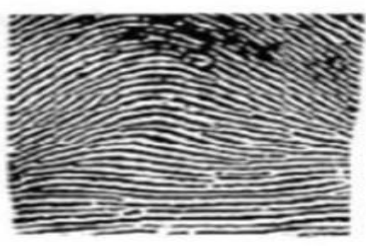

Arco (A)

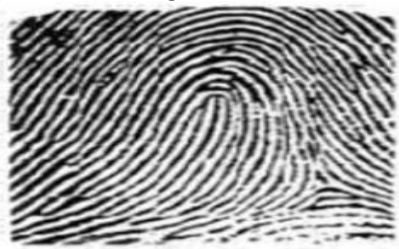

Presilha (L)

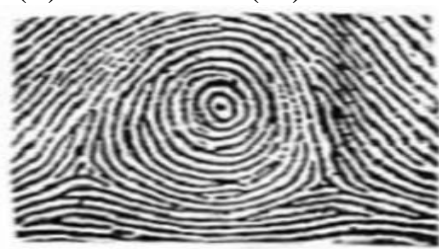

Verticilo (W)

Fig. 2: Values referring to the types of drawings of the fingers of the right and left hand $(n=24)$.

\begin{tabular}{|c|c|c|c|c|c|c|c|c|c|c|c|c|}
\hline Atleta & MDT1 & MDT2 & MDT3 & MDT4 & MDT5 & MET1 & MIET2 & MEIT3 & MET4 & MEIS & D10 & Förmula \\
\hline I & 2 & 1 & 0 & 1 & 1 & 1 & 1 & 1 & 1 & 1 & 10 & $L>W$ \\
\hline แ & 1 & 1 & 0 & 2 & 1 & 1 & 0 & 2 & 2 & 1 & 11 & $L=W$ \\
\hline III & 2 & 2 & 2 & 2 & 2 & 2 & 2 & 2 & 2 & 2 & 20 & $10 \mathrm{~W}$ \\
\hline IV & 1 & 1 & 1 & 1 & 1 & 1 & 1 & 1 & 1 & 1 & 10 & $10 \mathrm{~L}$ \\
\hline $\mathbf{v}$ & 2 & 1 & 0 & 1 & 1 & 2 & 0 & 1 & 1 & 2 & 11 & $\mathrm{~L}=\mathrm{W}$ \\
\hline v & 2 & 2 & 2 & 2 & 1 & 1 & 2 & 2 & 1 & 1 & 16 & $W>L$ \\
\hline viı & 0 & 1 & 1 & 1 & 1 & 1 & 0 & 1 & 1 & 1 & 8 & AL. \\
\hline vil & 2 & 2 & 2 & 2 & 2 & 2 & 1 & 1 & 2 & 2 & 18 & $W>L$ \\
\hline IX & 1 & 2 & 2 & 1 & 1 & 1 & 1 & 1 & 1 & 1 & 12 & $L>W$ \\
\hline$x$ & 2 & 0 & 1 & 1 & 1 & 1 & 1 & 1 & 1 & 1 & 10 & $L>W$ \\
\hline $\mathbf{x} \mathbf{I}$ & 2 & 1 & 1 & 1 & 1 & 2 & 0 & 1 & 1 & 1 & 11 & $L>W$ \\
\hline XII & 1 & 0 & 1 & 1 & 1 & 1 & 1 & 1 & 1 & 1 & 9 & AL \\
\hline xIII & 1 & 1 & 0 & 0 & 1 & 1 & 1 & 1 & 1 & 1 & 8 & AL \\
\hline XIV & 1 & 0 & 0 & 0 & 0 & 1 & 0 & 0 & 0 & 0 & 2 & AL \\
\hline $\mathbf{x v}$ & 2 & 1 & 2 & 2 & 1 & 1 & 2 & 2 & 2 & 1 & 16 & $W>L$ \\
\hline xvy & 2 & 0 & 0 & 0 & 0 & 0 & 0 & 0 & 1 & 0 & 3 & ALW \\
\hline XVIII & 2 & 2 & 1 & 2 & 2 & 1 & 2 & 1 & 1 & 1 & 15 & $L=W$ \\
\hline XVIII & 2 & 2 & 2 & 2 & 1 & 2 & 1 & 1 & 2 & 1 & 16 & $W>L$ \\
\hline $\mathbf{X I X}$ & 0 & 1 & 1 & 1 & 1 & 1 & 1 & 1 & 1 & 1 & 9 & AL \\
\hline $\mathbf{x x}$ & 2 & 1 & 2 & 2 & 2 & 2 & 1 & 1 & 1 & 1 & 15 & $L=W$ \\
\hline $\mathbf{x} \mathbf{x}$ & 1 & 1 & 1 & 1 & 1 & 1 & 1 & 1 & 1 & 1 & 10 & $10 \mathrm{~L}$ \\
\hline $\mathbf{x X \mathbf { X }}$ & 2 & 1 & 2 & 1 & 1 & 2 & 0 & 2 & 2 & 1 & 14 & $\mathrm{~L}=\mathrm{W}$ \\
\hline XXIII & 1 & 1 & 1 & 2 & 2 & 1 & 1 & 1 & 2 & 1 & 13 & $L>W$ \\
\hline $\mathbf{x X I V}$ & 1 & 1 & 1 & 2 & 1 & 1 & 0 & 1 & 1 & 1 & 10 & $L>W$ \\
\hline Médila & 1,46 & 1,08 & 1,08 & 1,29 & 1,13 & 1,25 & 0,83 & 1,13 & 1,25 & 1,04 & 11,54 & \\
\hline
\end{tabular}

Fig. 3: Mean values for the types of drawings and delta index according to the position in the field.

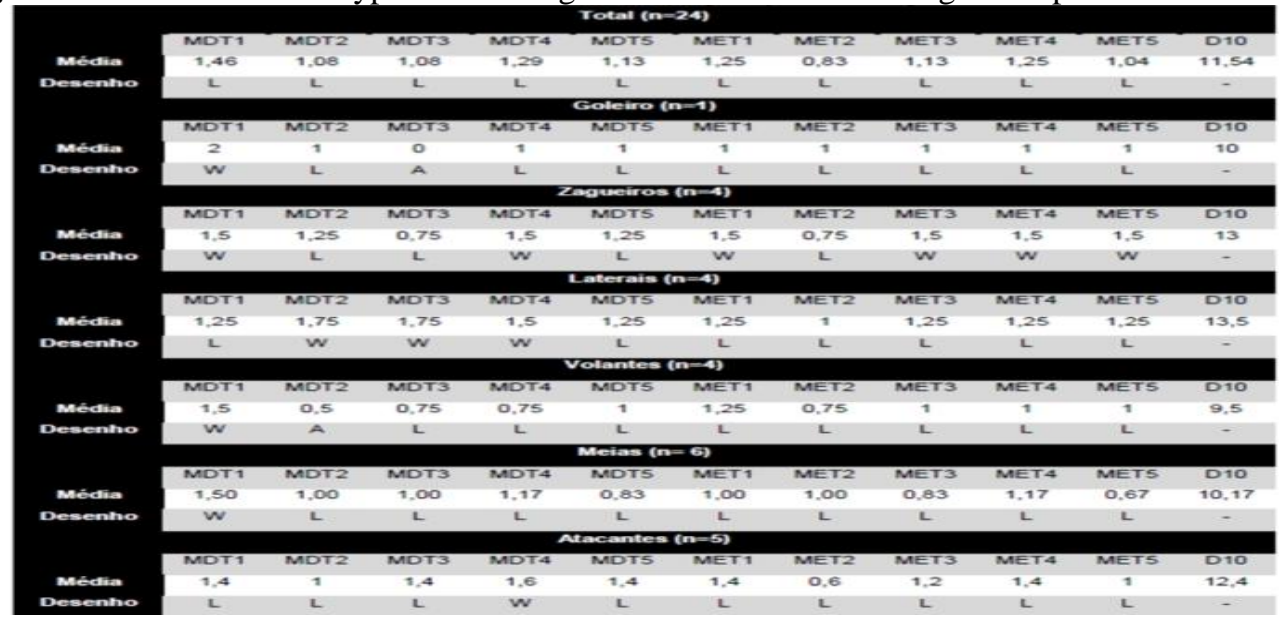

Fig. 4: Incidence of somatofunctional characteristics in different positions in the field.

\begin{tabular}{l|c}
\multicolumn{1}{c}{ Qualidades Fisicas/antropométrica } & Incidência \\
Estatura & $16,67 \%$ \\
Força & $45,83 \%$ \\
Velocidade & $62,50 \%$ \\
Força explosiva & $62,50 \%$ \\
Coordenaçäo & $37,50 \%$ \\
Resistência aeróbia & $37,50 \%$ \\
Resistência de velocidade & $37,50 \%$ \\
Agilidade & $33,33 \%$ \\
\hline
\end{tabular}


Fig. 5: Somatofunctional classification from the delta index by field position.

\begin{tabular}{llll} 
Posição & n & D10 & Classificação Somatofuncional \\
\cline { 2 - 5 } Goleiro & 1 & 10 & Velocidade; Força; força explosiva; e estatura \\
Zagueiro & 4 & 13 & Coordenação; Resistência de velocidade; e Agilidade \\
Laterais & 4 & 13,5 & Coordenação; Resistência de velocidade; e Agilidade \\
Volantes & 4 & 9,5 & Velocidade; e Força \\
Meias & 6 & 10,17 & Velocidade; Força; força explosiva; e estatura \\
Atacantes & 5 & 12,4 & Estatura; Velocidade; e Força explosiva \\
\hline
\end{tabular}

Fig. 6: Combination of digital formulas expressed as a percentage for the group.

\begin{tabular}{|c|cc|}
\hline \multirow{2}{*}{ Fórmula } & Quantidade & Porcentagem \\
\cline { 2 - 3 } L=W & 6 & $25,00 \%$ \\
LWW & 5 & $20,83 \%$ \\
10L & 1 & $4,17 \%$ \\
W>L & 2 & $8,33 \%$ \\
AL & 4 & $16,67 \%$ \\
ALW & 5 & $20,83 \%$ \\
\hline
\end{tabular}

Fig. 7: Ranking of dermatoglyphic indices and somato-functional indexes of futsal players $(\mathrm{n}=51)(\mathrm{DANTAS}$,

\begin{tabular}{|c|c|c|c|c|}
\hline \multirow[t]{2}{*}{ Classe } & \multicolumn{2}{|c|}{$\begin{array}{l}\text { Impressão } \\
\text { digital }\end{array}$} & \multicolumn{2}{|l|}{ Somatofuncional } \\
\hline & D10 & SQTL & Minimo & Máximo \\
\hline $\mathbf{I}$ & 6,0 & 22,0 & $\begin{array}{l}\text { Coordenação, Resistência de } \\
\text { velocidade; Agilidade; e Resistência }\end{array}$ & Força \\
\hline II & 9,1 & 86,2 & $\begin{array}{l}\text { Coordenação; resistência de } \\
\text { velocidade; e Resistência }\end{array}$ & Velocidade; e Força \\
\hline III & 11,1 & 119,1 & Coordenação; e Resistência & $\begin{array}{l}\text { Estatura; Velocidade; e Força } \\
\text { explosiva }\end{array}$ \\
\hline IV & 14,1 & 139,6 & Estatura; Velocidade; e Força & $\begin{array}{l}\text { Coordenação; Resistência de } \\
\text { velocidade; e Agilidade }\end{array}$ \\
\hline $\mathbf{v}$ & 16,1 & 150,1 & Força & $\begin{array}{l}\text { Coordenação; } \text { Resistência de } \\
\text { velocidade; Aqilidade; e Resistência }\end{array}$ \\
\hline
\end{tabular}

\section{Conclusion}

Selection and training of talent can not be based on empiricism. These works should be carried out in a scientific way and by prospecting. Selection of talent refers to understanding and operating the income emphatically as a result of the genetic potential of the individual and talent formation as a process of monitoring the development of the athlete with the correct use of anticipated knowledge of the possibilities and genetic tendencies added to the contribution of environment conducive Training. Football, as well as their physical training methodologies, have evolved a lot in recent decades. However, sports policies for the selection and formation of sporting talents are still based on subjective and empirical work.Physical trainers should use methodologies based on individual genetic potentials of athletes. Dermatoglyphics is a tool for evaluation and can be present in the stages of talent selection and training. This intervention may become more complete when related to other parameters, such as somatotype and sexual maturation, for example. However, further studies should be conducted in the search for a better understanding of the factors that involve genetic potential from fingerprints. Currently there is a lack in the literature of studies that relate the biometric markers to other physiological parameters, such as the relation with the types of muscle fibers.

\section{References}

[1] M.T.S. Böhme, Aptidão Física de Jovens Atletas do Sexo Feminino Analisada em Relação a Determinados Aspectos Biológicos, Idade Cronológica e Tipo de Modalidade Esportiva Praticada, doctoral diss., Universidade de São Paulo, São Paulo, SP, 1999.

[2] E.H.M. Dantas, M.N.D. Portal, and L.A.V. Santos, Plano de expectativa individual: uma perspectiva científica para a detecção de talentos esportivos, master diss., Universidade Castelo Branco, Viçosa ,MG,2004.

[3] A.K Moskatova, Aspectos Genéticos e Fisiológicos no Esporte: seleção de talentos na infância e adolescência.(Rio de Janeiro, RJ: Grupo Palestra Sport, 1998.

[4] C.Bouchard, and G.Lortie, Heredity and endurance performance. Sports Med Auckland, 1(1), 1984,38-64. 
[5] A.A.M.Ferreira, Perfil dermatoglífico, somatotípico e das qualidades físicas de atletas brasileiros de corrida de orientação de alto rendimento, doctoral diss., Universidade Castelo Branco, Rio de Janeiro, RJ, 2004.

[6] J.P.Borin, Utilização da discriminação gráfica de fisher para indicação dos dermatóglifos como referencial de potencialidade de atletas de basquetebol, doctoral diss., Universidade Estadual de Campinas, Campinas,SP,2002.

[7] J.Vucettich, Dactiloscopia comparada, Boletin Museu Nacional. n.7, p. 19, 1904.

[8] K.Bonnevie, Studies on papillary patterns of human fingers. The Journal Genetics, 15(1), 1924,1-11.

[9] S.B. Holt, Quantitative genetics of dermal ridge patterns on finger. Acta Genetics, 6(3), 1957, 473-479.

[10] H.Cummins, and C.Midlo . Palmar and plantar dermatoglyphics in primates, (Philadelphia: Dover Publications, 1961).

[11] BRASIL. Ministério da Saúde, Conselho Nacional de Saúde. Resolução n. 196/96, de 10 de outubro de 1996. Estabelece as diretrizes e normas regulamentadoras de pesquisas envolvendo seres humanos. Brasília, 1996. 